\title{
LA EXPERIENCIA DEL ANTISEMITISMO EN SEIS TESTIMONIOS DE SOBREVIVIENTES DE LA ShoÁ albergados en ChILE.
}

\author{
Silvana Vetö \\ silvana.veto@gmail.com \\ Doctorante en Historia, Universidad de Chile
}

\section{Resumen.}

Este artículo aborda los testimonios de seis sobrevivientes de la Shoá que se albergaron en Chile. Ellos son trabajados desde la óptica de la experiencia del antisemitismo, buscando con ello rescatar, más allá del ámbito conceptual, la voz y memoria de quienes lo han sufrido. Los testimonios son caracterizados, primero, desde variables sociodemográficas y biográficas, para luego ser abordados a partir de algunos aspectos claves del antisemitismo que resultaron centrales en los testimonios: las experiencias iniciales de antisemitismo y el desmoronamiento del mundo europeo y de los lazos identitarios. Los resultados del análisis arrojan importantes diferencias entre los sobrevivientes provenientes de Alemania y aquellos provenientes del resto de Europa. EI trabajo concluye con una reflexión referente a las posiciones ético-políticas sobre racismo y discriminación que podrían resultar de la experiencia del antisemitismo.

Palabras clave: antisemitismo, racismo, experiencia, testimonio, sobrevivientes, Shoá.

\section{Abstract.}

This article discusses the testimonies of six survivors of the Shoah that found shelter in Chile. They are approached from the perspective of the experience of anti-Semitism, thereby seeking to rescue, beyond the conceptual level, the voice and memory of those who have suffered it. The testimonies are characterized, first, from demographic and biographical variables, before being tackled from several key aspects of anti-Semitism that resulted central to the evidence: initial experiences of antisemitism and the collapse of European world and the bonds of identity. The analysis results show significant differences between survivors from Germany and those from the 
Silvana Veto.

La experiencia del antisemitismo en seis testimonios de sobrevivientes De la Shoá albergados en Chile.

rest of Europe. The paper concludes with a reflection about the ethical and political positions on racism and discrimination that might result from the experience of antisemitism.

Key Words: antisemitism, racism, experience, testimony, survivors, Shoah. 
En esta trabajo se abordarán seis de los cuarenta testimonios registrados a la fecha por Voces de la Shoá, proyecto principal de la Fundación Memoria Viva, inaugurado en 2008, que tiene el objetivo de registrar, preservar y difundir los testimonios de los sobrevivientes de la Shoá que se albergaron en Chile'.

En esta ocasión, los testimonios serán tratados desde la óptica de la experiencia del antisemitismo, esperando de esta manera rescatar, más allá del ámbito conceptual, aunque incluyéndolo, las voces y la memoria de quienes lo han sufridoii.

Comenzaré por caracterizar los testimonios revisados desde sus variables sociodemográficas y biográficas, para luego abordarlos a partir de algunos aspectos claves del antisemitismo, tal como éste ha sido trabajado por autores como Saul Friedländer, Zygmut Bauman, Tzvetan Todorov y Michel Wieviorka.

Los testimonios corresponden a cinco hombres y una mujer, tres de procedencia alemana, uno polaca, uno checoslovaca y uno holandesa, nacidos entre 1913 y 1933. Sus experiencias más significativas incluyen la Noche de los Cristales Rotos, el campo-gueto de Theresienstadt, campos de concentración como Bergen-Belsen, Buchenwald, Mauthausen y Auschwitz. La mayoría de ellos provienen de familias de clase media, salvo uno que se autodefine de familia "aburguesada". Dos de ellos formaban parte de familias religiosas, mientras que los otros cuatro integraban familias muy asimiladas que sólo celebraban las fiestas más importantes del judaísmo o no celebraban ninguna en absoluto. Como podrá apreciarse en lo que sigue, estas variables son importantes de incorporar, por cuanto inciden de distintos modos en la experiencia vivida del antisemitismo.

Antes de ir a los testimonios de los sobrevivientes, algunas definiciones básicas. Es sabido que el antisemitismo existía de antiguo en Europa, pero es posible distinguir bastante claramente el 
antisemitismo "nazi", de otros antisemitismos de carácter religioso o incluso secular que aún no tomaban los ribetes del racismo propiamente tal (Friedländer, S. 1997). Con el nazismo, nos hallamos frente a un antisemitismo que no se sostiene únicamente del prejuicio y la discriminación. El antisemitismo nazi es, en términos de Wieviorka (2009) diferencialista; no busca someter u oprimir al Otro para explotarlo, por ejemplo, sino que llega al extremo del exterminio. No se conforma con la exclusión social y la segregación espacial, sino que debe aniquilar. Esto, fundamentalmente, porque el judío es definido en términos raciales: es un enemigo amenazante y peligroso, que cuesta distinguir del "nosotros", y que es irredimible e ineducable, ya que es su "raza" la que lo determina, y ésta se define, precisamente, como invariable. El antisemitismo nazi es, pues, un antisemitismo racial (Friedländer 1997), pero no sólo eso, ya que además de su vertiente cientificista, como la llama Todorov (1991), tiene una fuerte "dimensión mística", que transparenta los resabios del antisemitismo religioso (Friedländer 1997). El "Reich de los mil años" o la Volkgemeinschaft de Hitler, constituyen un proyecto utópico, mesiánico, que no puede llevarse a cabo si los judíos están aún sobre la tierra. El tiempo mesiánico advendría una vez Alemania y luego el mundo, fueran liberados de los judíos. Se trata, entonces, de una utopía que se sostiene en el genocidio, como diría Bauman (2008) y que es redentora a la vez. De allí que Friedländer (1997) Ilamara al antisemitismo practicado por lo nazis, "antisemitismo redentor". Es exclusivamente a este antisemitismo, racista y redentor, al que haremos referencia en lo que sigue.

El primer aspecto de los testimonios en que quisiera detenerme, tiene que ver con las experiencias iniciales del antisemitismo nazi, es decir, con el modo en que estos sobrevivientes experimentaron lo que podría denominarse sus "primeras fases": la construcción de lo que Feierstein (2000) llama "otredad negativa", o lo que Bauman (2008) denomina "judío conceptual", así como el hostigamiento y exclusión de la vida social y el aislamiento y segregación espacial.

Para aquellos sobrevivientes procedentes de la ex Checoslovaquia, Polonia y Holanda, las primeras experiencias de este antisemitismo que acabo de delinear, inician en 1939, año en que se desata la Guerra. Estas experiencias son generalmente conectadas a la dificultad de advertir el verdadero peligro al que conllevaban dichas primeras fases, a saber, las políticas de franco exterminio, habitualmente conocidas como "Solución Final", que vendrían a efectuarse más tarde. 
“...empezaron con una política, todavía no cámaras de gas, campos de concentración..., pero no se vino a nadie la idea que hicieron, estudiaron paulatinamente; hoy no puedes trabajar..., no compra donde judíos..., no podía ejercer ni médico, ni abogado, ni nadie, entonces el mundo no entendió..." (Polonia)

"[la vida en Praga a partir del 1ํ de septiembre del '39] ... era siempre un poquitito menos, un poquitito menos, un poquitito menos... Y después, en el '41, ya teníamos que dejar nuestro departamento y tenemos que concentrarnos todos los judíos en el centro de Praga... y después llego Theresienstadt. ...Y Theresienstadt no era nada, si uno después había visto, era un jardín de nenes, de Edén." (ex Checoslovaquia)

"Los alemanes tenían una política... una estrategia muy inteligente; hicieron las cosas muy de a poco, para no inquietar demasiado a la población. Así que el primer año, el año '40... no pasó mucho. Empezó una ley de que los judíos deberían poner una estrella amarilla, todo el mundo se asustó, pero en realidad no pasó nada. Después vino una ley que los que tienen estrella pueden solamente comprar en los establecimientos entre 3 y 5 de la tarde... y así de a poco comenzaron a restringir la libertad de movimiento. Después un año más tarde vino una ley que todos los judíos deben ir a un barrio, una especie de gueto... hasta el año 42 fui a un colegio público y tuvo que ir a un colegio judío, que tampoco afectó mayormente, o sea son cambios, pero todo era aguantable, siempre con varios meses de intervalos entre una medida y otra medida. Esto no ha sido muy bien comprendido todavía en el mundo, por eso estoy diciendo esto, porque hay mucha gente que preguntan, sobre todo los que no estuvieron ahí, «¿cómo los judíos no se defendieron?»... sobre todo porque lo que pasó no era tan grave para hacer una revuelta, ¿me entiende? La diferencia entre los holandeses y los judíos holandeses no era tan grande, las cosas que yo le estoy contando, entonces ya cuando las cosas empezaron a ser muy graves, ya no había manera de defenderse." (Holanda)

Para los sobrevivientes originarios de Alemania, la experiencia fue distinta, fue experimentada más prematuramente que en otras parte de Europa, y con un sello más marcado de 
"desmoronamiento", como luego veremos. Esta experiencia más prematura se liga, al contrario de los sobrevivientes de otras partes de Europa, a la posibilidad de tener "un diagnóstico más exacto y una percepción mayor del peligro que estaba pasando".

En Alemania, estas experiencias son anteriores a 1939, prácticamente contemporáneas a los inicios del Tercer Reich, con la propaganda, las políticas de exclusión de la vida social, la segregación espacial, que se vivían en la cotidianidad. Sin embargo, dichas experiencias se intensifican y se vuelven menos disponibles a la denegación, a partir de la Noche de los Cristales Rotos, en noviembre de 1938.

“... cuando Hitler llegó al poder y todo empezó a cambiar, no de un viaje, pero notoriamente... en el colegio, yo era en un colegio estatal... de Berlín, empezó muy luego a notarse, ¿por qué? porque el esquema y la idea de Hitler era agarrar a la juventud y la agrupó en la Hitlerjugend y ahí fueron ideologizados y trajeron esto a colación en el colegio, en el mundo donde vivían y empezó rápidamente a notarse que de a poco, de a poco, voy siendo excluido de la vida social del curso... primero uno que otro garabato, acusaciones de tipo racial, y después la exclusión... Lo mismo pasó en la calle... En esta pequeña plaza, donde miraba nuestra casa, por ejemplo, era típico, había unos cuantos escaños, como en todo parque o plaza de Alemania, y un día vinieron obreros municipales, pintaron amarillos los escaños, uno, que era para judíos, y ningún judío puede sentarse en un parque en un escaño que no era pintado para ellos."

“... siempre tenían la esperanza de que esta era una situación transitoria, que el régimen iba a pasar, que no podía haber tanta locura. Ahora, eso debe haber sido hasta noviembre del '38, cuando a mi padre lo detuvieron en la madrugada y se lo llevaron a Buchenwald."

"Un decreto de Hitler que fue publicado y teníamos que dejar todos los judíos, ya no podían terminar el tercer semestre. Un decreto, y me fui. No tenía que protestar, contra un decreto de este dictador no había nada que hacer, entonces había que... callado, había que desaparecer. En todo Alemania ... y después también desaparecían todos los docentes, los profesores. Limpiaron la vida cultural de la influencia semita, judía..." 
“Justamente en ese momento llegó la debacle con Hitler, que los judíos tenían que dejar todo y había que prepararse para huir o para salir de Alemania... y este fue la razón, la muerte del señor Rath, alemán de la embajada, para empezar la persecución judía física. Así fuimos con un decreto todos los judíos jóvenes hasta 25 años, 26 años, fueron tomado prisioneros y despachado a un campo de concentración. Esta era la famosa noche del cristal."

Por otra parte, estas personas destacan el desmoronamiento que implicó para ellos y sus familias la instalación y el desarrollo de este antisemitismo de nuevo cuño. Se trataba, como dije anteriormente, de familias muy asimiladas que se autodefinían principalmente como alemanas. En concordancia con algunos autores, en estos testimonios se destaca que la vida de los judíos en Alemania antes de Hitler era bastante mejor que en Europa oriental, y que la mayoría de los ciudadanos alemanes ordinarios (es decir, que no pertenecían al partido nazi, a las juventudes hitlerianas o a las SS) no eran especialmente antisemitas, o no al menos en comparación con los polacos o los rusos.

“... del punto de vista de matar judíos en forma esporádica, los rusos y los polacos, ganaron lejos. Los pogroms en 1860, 70, 90, eran terribles y esto en Alemania, por supuesto, no sucedía, así cada uno que pudo vine a Alemania, vino, y se sentía cómodo, aceptado, porque nadie te mataba en la calle, uno que otro te echaba garabatos antisemitas, pero en general no..."

"Habían ya varias generaciones que tenía libertad para vivir en la ciudad que querían, para estudiar, para trabajar, para desempeñarse como los demás ciudadanos."

“...en Alemania existía siempre, antisemitismo siempre, el antisemitismo social de la clase alta, fuera que sean grandes industriales o banqueros, pero la clase media estaba muy, muy benevolente con los judíos... había una cierta bienestar y había un ambiente muy agradable. Mis padres tenían más amigos cristianos que judíos.

La gente con que teníamos contacto no eran antisemitas. Este antisemita fue creado artificialmente y fue inculcado a la gente." 
Podría decirse, siguiendo a Friedländer (1997), que con el antisemitismo nazi, el esquema de la asimilación dejó de ser viable. En un contexto en que las diferencias eran conceptualizada cada vez menos como religiosas o etnoculturales, y cada vez más como raciales, la asimilación ya no rendía frutos.

"Entre los judíos alemanes se produjo, pero eso lo sabemos ahora, se produjo un fenómeno que en inglés se llama wishful thinking, que se crearon una idea, un ambiente, y creían que era realidad, y no era. Ellos creían que eran 100\% aceptados, y no fueron nunca 100\% aceptados."

De esta manera, el advenimiento de un antisemitismo que no se conformaba con manifestaciones populares esporádicas (del tipo pogroms), que no era marginal, sino el núcleo mismo de la ideología nazi (Arendt, H. 1982), es decir, del Estado, y que, por lo tanto informaba y conformaba políticas públicas de todo tipoiii, implicó para los judíos alemanes una sorpresa de la índole de lo traumático, algo completamente inesperado que no se puede integrar en los esquemas habituales de pensamiento:

“... nuestros padres, que han vivido 50 años muy bien allá y suponían que era el ambiente de ellos, ellos pertenecen al ambiente, entonces para ellos se desmoronó un mundo completo, mientras para nosotros se desmoronó la posibilidad de un mundo, que todavía no existía. Entonces, lo que para nuestros padres era el desmoronamiento de un mundo existente, para nosotros esto fue la búsqueda de un mundo para uno."

Este último señalamiento nos dirige hacia otro aspecto presente en los testimonios: el derrumbamiento del mundo europeo y de los lazos identitarios involucrados. Ello comienza sin duda con la intervención de los nombres y las ciudadanías. Los judíos alemanes primero, y aquellos de la Europa ocupada luego, perdían su nacionalidad, pasaban a integrar esa problemática categoría del apátrida -que Hannah Arendt (1991) trabajó tan elocuentemente-, a quien ningún Estado protege. Sus pasaportes eran sellados con una "J" que connotaba su 
judeidad, y sus nombres eran sucedidos por Israel para los hombres, y Sara para las mujeres. Ya una vez en los campos la desindividuación era más incisiva aún: números tatuados sustituían los nombres. Esta pérdida de los más fuertes lazos identitarios como son el nombre y la nacionalidad, implicó que una vez terminada la guerra, Europa no fuera más una posibilidad de vida:

"Después de la guerra, lo único que queríamos... era irnos, irnos, irnos, no quedarnos más en Europa.” “...nunca quería tener otra vez mi pasaporte checo...”

"Si eran jóvenes, lo único que querían era ir a Israel, a Palestina, hacer Aliyá. Lo único. No querían más que ver con Europa, esto no era ya ningún futuro para ellos."

En uno de los testimonios, esta pérdida de lazos identitarios con Europa se muestra de modo incluso más dramático, por cuanto la persona en cuestión es exiliada de Chile (en 1974) y, sin haberlo escogido, debe regresar a su país de origen, Alemania. Las paradojas de la historia hacen que diplomáticos alemanes exijan su libertad por considerarlo ciudadano alemán y se comprometan en su cuidado. Sin embargo, aún después de vivir alrededor de 10 años en Alemania, no vuelve a considerarse alemán. "Mi situación era la de exiliado chileno", explica.

En los testimonios revisados, este derrumbamiento y desidentificación parece tener como efecto dos tendencias divergentes. La primera es la tendencia a la integración: "Judíos sí, pero en la casa, afuera queremos ser chilenos". Se trata, una vez más, de la asimilación, pero esta vez a Chile. Es una tendencia más cercana, además, al silencio respecto de la experiencia del Holocausto:

"Nosotros, cuando terminó todo no queríamos saber nada, queríamos vivir, vivir, vivir. Tampoco, yo creo que no soy la única, no contaba mucho a mis hijos..., porque no queríamos, queríamos vivir."

La segunda es a la creación, más cercana a la reivindicación y a la acción. Se trata del intento de crear un nuevo mundo en el cual vivir, recogiendo la experiencia del Holocausto: 
"... no temo, enfrento a todos yo solo, porque voy a luchar, prometí, de AuschwitzBirkenau...: si alguien de nosotros va a estar vivo, vamos a trabajar para mejor mundo para todos, sin distinción de credo, de raza, de religión..."

"En el fondo saben que había un Auschwitz, pero ellos..., lo queremos negar, no me vengan con historias, con películas, yo quiero pensar esto, yo odio los judíos. Entonces, difícil convencer gente así. Y así decía Goebbels, uno de los colaboradores de Hitler, decía que la mentira, que si se repite bastantes veces, bastante bien, se aconcha, al final queda. Tenemos que luchar contra eso. Eso es. Tenemos que educar..."

Para terminar, quisiera hacer una reflexión en torno a algo que nunca ha dejado de desconcertarme: que la experiencia del Holocausto no sea siempre, como mi ingenuidad probablemente me alentaba a creer, la fuente certera de una posición ética y moral que rechaza y lucha contra el racismo y la discriminación, los campos de concentración y los genocidios allí donde aparezcan, sean quienes sean su víctimas, y bajo las razones que sea. Escuchando los testimonios, me enfrenté a este problema bajo la forma del apoyo, pasivo o activo, de algunos sobrevivientes, a un régimen dictatorial y violador de derechos humanos como el de Pinochet. Para intentar articular los mecanismos de esto que a mis ojos aparece como una incoherencia flagrante, he podido echar mano de algunas ideas sobre las formas contemporáneas de racismo o lo que llamaré "lógica del racismo".

Puede decirse, con G. Fredrickson (2002), que luego de la caída del nazismo, de los procesos de descolonización y de algunos avances científicos, el racismo ha sido mundialmente desacreditado. No obstante, a partir de ese momento, una nueva faceta del racismo ha comenzado a dibujarse. Paradójicamente, ésta ha abandonado el concepto de "raza", en favor de conceptos esencialistas de la cultura y las etnias (Bokser, J. 2001), así como también de las clases sociales y las orientaciones políticas. Es entonces cuando el racismo se vuelve más lábil e insidioso, requiriendo de definiciones más estructurales que permitan capturarlo en cada una de sus expresiones. Para cercar este nuevo fenómeno de un "racismo sin razas", como se expresa M. Wieviorka (2009), podemos hablar más bien de "lógica del racismo". Ésta se encuentra allí donde 
la hostilidad, la discriminación y la violencia se justifican a través de la referencia a diferencias entre un "nosotros" y un "los otros" de cualquier índole; ya sean culturales, sociales, políticas, étnicas o sexuales, que se conceptualicen además como permanentes, inmodificables y determinantes. Allí donde hallemos esta lógica, nos encontramos frente a la posible semilla del genocidio ${ }^{\text {iv }}$.

Analizando la actitud racista que el personaje principal de Maus, Vladek Spiegelman, sobreviviente de Auschwitz, manifestaba hacia un afroamericano en Nueva York, James Young escribió:

"Y si el Holocausto no ilumina a sus víctimas, ¿cómo su historia iluminaría a la generación siguiente? Es una ironía que contiene un juicio clarísimo: el Holocausto fue una irredimiblemente terrible experiencia en ese entonces, tuvo un efecto terrible en las vidas de muchos sobrevivientes, y hoy no dota a sus víctimas con una mayor autoridad moral." (Young 1998, p. 696)

Ni la sobrevivencia, ni el hecho de formar parte de un grupo minoritario que ha sido sometido a la lógica racista, asegura una actitud y una posición ético-política antirracista. No se puede, por ende, descansar en dichas experiencias del pasado y dormirse con la conciencia tranquila en el presente, es necesario que "nosotros", cualquiera que sea, pueda identificarse con "los otros", para ver en sus experiencias, ecos de las propias y entonces advertir en sus luchas, las nuestras. 


\section{BIBLIOGRAFÍA}

1. ARENDT, Hannah.

— Los orígenes del totalitarismo. Madrid, Alianza. 1982.

_ Auschwitz et Jerusalem. París, Deuxtemps Tierce. 1991.

2. BAUMAN, Zygmut. Modernidad y Holocausto. Madrid, Sequitur. 1998.

3. BOKSER, Judit. "El antisemitismo: recurrencias y cambios históricos". Revista Mexicana de Ciencias Políticas y Sociales. XLIV (182-183): 101- 132, 2001.

4. FEIERSTEIN, Daniel. Seis estudios sobre genocidio. Análisis de las relaciones sociales: otredad, exclusión y exterminio. Buenos Aires, EUDEBA. 2000.

5. FREDRICKSON, George M. Racism: A Short Story. New Jersey, Princeton University Press. 2002.

6. FRIEDLÄNDER, Saul. Nazi Germany and the Jews. The Years of Persecution, 1933- 1939. NYC, Harper Collins. 1997.

7. TODOROV, Tzvetan.

— Nosotros y los otros. México, Siglo XXI. 1991.

— Los abusos de la memoria. Barcelona, Paidós. 2000.

8. WIEVIORKA, Michel. El racismo: una introducción. Barcelona, Gedisa. 2009.

9. YOUNG, James E. “The Holocaust as Vicarious Past: Art Spiegelman's «Maus» and the Afterimages of History". Critical Inquiry, 24 (3): 666-699, 1998. 


\section{NOTAS}

¡ Véase: www.vocesdelashoa.cl

ii Los testimonios serán trabajados de manera anónima. Cuando la argumentación lo requiera, se precisará el país de origen de los testigos.

iii Esta distinción sigue aquella establecida por Wieviorka (2009, pp. 89-94) entre violencia infrapolítica y violencia política.

iv Proceso que la película alemana La Ola (Gansel, 2008), muestra muy elocuentemente. 